Citation: Anoop S Kumar (2021) Adaptive market hypothesis: An empirical analysis of the Wine Market. Wine Economics and Policy 10(2): 99-109. doi: 10.36253/wep-9492

Copyright: $@ 2021$ Anoop S Kumar. This is an open access, peer-reviewed article published by Firenze University Press (http://www.fupress.com/wep) and distributed under the terms of the Creative Commons Attribution License, which permits unrestricted use, distribution, and reproduction in any medium, provided the original author and source are credited.

Data Availability Statement: All relevant data are within the paper and its Supporting Information files.

Competing Interests: The Author(s) declare(s) no conflict of interest.

\section{Adaptive market hypothesis: An empirical analysis of the Wine Market}

\author{
Anoop S Kumar \\ Gulati Institute of Finance and Taxation, Chavadimukku, Sreekariyam, Thiruvanan- \\ thapuram, Kerala, India.Email: askumar@gift.res.in
}

\begin{abstract}
We test the nature of weak form informational efficiency present in the wine market using daily return of LIV-EX 50 index from 1/1/2010 to 12/6/2020. First, we employ a number of statistical tests including variance ratio tests, tests for linear and non-linear dependence and Hurst coefficient. The tests are applied on the full dataset and on four non overlapping sub-samples of equal length. The variance ratio tests provide a mixed regarding informational efficiency. Evidence of non-linear dependence in the return series was found. The Hurst coefficient values confirm the presence of long run persistence in the wine market. Based on the mixed evidence, we test the possibility of adaptive nature of the wine market. We employ the newly proposed Adaptive Index (AI) to quantify the degree of information inefficiency in the wine market at any instance. Our results confirm that wine market is adaptive and periodically shifts between states of efficiency and inefficiency. The wine market is found to be relatively free from the Covid-19 induced shock and the safe haven property of wine is thus confirmed. Finally, impact of various macroeconomic and financial events on wine market efficiency is identified by using AI.
\end{abstract}

Keywords: LIV-EX 50, EMH, adaptive markets, VR tests.

\section{INTRODUCTION}

Ever since its inception, the Efficient market hypothesis (EMH henceforth), proposed by Fama [1] has been at the center of many academic discussions. Fama proposed a financial market that is informationally efficient. He postulated that asset prices contain all relevant information and they instantaneously absorb all the fresh information. EMH talks about a market populated by rational investors, optimally using all the information available to them. If a market is informationally efficient, any deviation from the asset's equilibrium value should be temporary, as market participants would instantaneously make use of any new information signal. In such a scenario, the possibility for arbitrage is absent. Fama postulated that EMH has three versions. The first version is called weak form EMH. In weak form EMH, current price of an asset contains all past price information. In semi-strong form $\mathrm{EMH}$, current price of an asset reflects past price information and all publicly available information. In strong form EMH, current prices include past price information, public and 
private information. Among these three forms, weak form EMH is the easiest to verify. Therefore, the current analysis is limited in that aspect.

As mentioned earlier, EMH in its weak form states that current price of an asset contains all information pertaining to its past prices. In such a scenario, price fluctuations are transient and hence, extreme price fluctuations can be ruled out. In that case, the asset's return series should follow a geometrical Brownian motion or random walk. If an asset is weak form efficient, we cannot employ past prices to predict future value. For an investor, it will not be possible to gain abnormal profits in the long run. If the market is informationally inefficient, there is scope for investors to make abnormal profits using appropriate strategies.

Empirical validation of weak form EMH resulted in mixed results across different financial markets. The varying outcomes are often attributed to the differences in sample size, statistic used, and the regional factor [2]. Moreover, most of the test statistics are binary in nature, i.e. the series is either weak form efficient or not. These issues encouraged researchers to investigate for alternate planations. Lo [3] argued that informational efficiency is not a static concept. Rather, it is time varying in nature. Lo proposed Adaptive Market Hypothesis (AMH henceforth) to reconcile EMH and assumptions from behavioral economics. He proposed that the market participants evolve. Further, they adapt according to the market conditions and structural changes. A market switches between states of efficiency and inefficiency if it is adaptive. Modeling dynamic nature of information efficiency in a financial market has its own practical uses. If one can identify the states of inefficiency, it is possible to apply relevant trading strategies and make a profit.

AMH have been verified in Equity markets [3-6] Forex markets [2,7], Commodity markets $[8,9]$ and cryptocurrency markets $[10,11]$. Here, our purpose is to test the validity of $\mathrm{AMH}$ in the fine wine market. Of late, fine wine has emerged as an alternative investment option. The literature provides ample evidence of investment potential of fine wine. In the following paragraphs, we discuss select studies that analyzed this aspect.

[12] employed the data from auctions at the Chicago Wine Company for the period of 1996 to 2007 and studied the evolution of wine prices. They constructed wine indices and found them to be cointegrated. Further, they found that wine returns and equity returns are not significantly correlated. Using the repeat sales regression model, [13] estimated the return to the Australian wine. $\mathrm{He}$ found that the wine returns are low compared to other financial assets. However, in spite of lower returns, wine is found to have diversifier property.
[14] compared from results from repeated sales regression model, hedonic pricing model and a hybrid model using Australian fine wine price data. The results suggested that hybrid model is way to incorporate Australian wines in a diversified portfolio in comparison with repeated sales regression and hedonic approach. Employing a threshold cointegration approach, [15] studied the interaction between Wine and stock markets of Australia, France, Chile, China and the US. The results indicated cointegration between wine and stock markets. Further, the speed of adjustment of the wine index for US and France was found to be slower compared to the stock market index, indicating that wine prices may be predictable in the short-run and informed traders can anticipate price movements and make profit.

[16] used Australian wine auction price data and showed that the estimation method has a significant impact on the wine return distribution and the type of diversification benefit test employed determines the extent of diversification potential of wine. They found that employing the efficient frontier method along with bootstrapped confidence intervals provide the best results regarding the diversification aspect of wine. Using a historical database for five long-established Bordeaux wines, [17] studied the impact of aging on wine prices and its potential as a long-term investment asset. They found that wine returns underperform compared to equites, but performs better compared to government bonds.

Employing cointegration methods and causality tests, [18] studied the short-term and long-term price linkages between fine wine and equity markets. Instead of wine index data, they employed auction price data of world's mostly traded vintage pairs. They found that the wine prices and global equity markets move together. Further, the causality test results revealed that wine prices influence each other. [19] employed dynamic conditional correlation GARCH model and studied the relationship between fine wines and equity indexes returns for United States, United Kingdom, Germany, France, and Japan. The study found evidence that fine wine exhibit hedge and weak safe haven properties against equity price fluctuations.

[20] analyzed the time varying risk premium related to fine wine investments in the context of financial crisis by employing a conditional CAPM model and a multivariate GARCH model. They found Boudreaux fine wine prices to be more volatile during financial crisis and less volatile during stable periods. Further, they found nonFrench wines to exhibit an inverse volatility trend while compared to French wines. Using Dynamic conditional correlation model, [21] analyzed the properties of fine 
wine as a hedge and safe haven instrument against UK stock price fluctuations. They found that wine can act as an effective hedge against stock price fluctuations. However, wine could not act as a safe haven against market turmoil.

[22] analyzed the role of Wine in investment portfolios for the French market. Using Liv-Ex and WineDex index data along with equity and bond prices, they employed mean-variance portfolio optimization approach and modified value-at-risk approach. They found that inclusion of wine in the investment portfolios increases the portfolio performance. Further, they suggested that wine is an ideal investment asset for riskaverse investors. Using Engle-Granger and Johanson cointegration methods, [23] studied the nature of cointegration between fine wine, non-fine wine and equity markets. They used Liv-Ex 100 index for fine wine prices, Mediobanca Global Wine Industry Share Price for normal wine, and the MSCI World Index to proxy the stock market. They found absence of co-integration between the series and confirmed the existence of diversification benefits of wine.

[24] analysed the long-term co-movement between the fine wine market and world equity markets by applying a cointegration based approach for a period of 21 years. They found statistically significant cointegration between emerging markets and fine wine markets. They found causal relationship from Emerging equity markets to wine markets, indicating that the slowdown of emerging countries can have an adverse effect on the fine wine market. Further, China was identified as a main driver of fine wine prices.

[25] studied the investment diversification potential of wine by employing portfolio diversification methods such as mean-variance optimization and stochastic dominance method. Their findings suggested that wine is the best individual investment asset in comparison to equities, bonds, gold, and housing. Further, they found that the investors prefer wine-included portfolios compared to without-wine portfolios in the absence of short selling. [26] employed auction hammer prices for the years 1996-2009 and constructed wine price indices. From the analysis, they found that fine wine yields higher return and exhibits low volatility compared to stocks. Further, they found that wine prices are mainly influenced by macroeconomic events than market risk.

From the literature, it is clear that wine is effectively used as an investment option. It can be used as a diversifier to reduce investment risk. Fine wine is considered as an investment option because it acts as a store of value. As Wine prices are often affected by non-economic factors such as the brand, year of vintage, grape composi- tion and production process [27], it can be used as an effective hedge and safe haven against portfolio fluctuations $[19,21]$.If wine is to be included in an investment portfolio, it is important to confirm whether wine prices are efficient or adaptive. If it is informationally efficient, the investor only needs to be concerned with the systemic risk, and the portfolio could be passively managed. If the markets are dynamically efficient, then there is nonsystemic risk and the portfolio will need to be actively managed.

There is a serious dearth of studies discussing informational efficiency of the wine prices. So far, we have come across only the pioneering study by Bouri et al. [29]. Here, the author used a set of unit root tests and found that wine market is informationally inefficient if structural breaks are considered. However, there is mounting evidence against static nature of information efficiency/inefficiency across other financial markets as mentioned earlier. Therefore, it is only logical for us to check the same for wine market. We aim the present study at that direction. We structure rest of the article as follows. Section 2 discusses data and methodology used. In section 3, we discuss the results. We present our concluding remarks in section 4 .

\section{DATA AND METHODS}

Daily returns of LIV-EX 50 index from 1/1/2010 to $12 / 6 / 2020$ is used for the analytical purposes. We select LIVE-EX 50 index as it includes price movement of most heavily traded commodities in the wine market. Therefore, it can act as a suitable proxy for studying market dynamics. The methodology comprises two parts. First, we statistically test the possible presence of weak form market efficiency using six variance ratio tests and two tests for serial dependence. In the second part, we capture the dynamic nature of informational efficiency by employing a newly constructed index. Brief description of the tests employed are provided in the forthcoming paragraphs.

\subsection{Variance ratio tests}

Variance Ratio (VR) tests occupy a prominent position among the methods to test for weak form informational efficiency in a time series. Lo and McKinlay [30] proposed the first VR test. Later, there were many extensions and modifications. Here, six commonly used VR test results are employed. Brief test descriptions are given in the following paragraphs. 


\subsubsection{Lo and McKinlay VR Test}

In Lo and McKinlay [17] , RWH for a time series $\mathrm{X}_{\mathrm{t}}$ is shown as:

$X_{t}=\mu+X_{t-1}+\varepsilon_{t}$

$\mu$ is the constant and follows an i.i.d normal distribution with zero mean and variance $\sigma^{2}$.

Here, the null hypothesis is stated as:

$H: \varepsilon_{t i}$ i.i.d. $N\left(0, \sigma^{2}{ }_{o}\right)$

Then, variance at $\mathrm{k}^{\text {th }}$ lag shall be $\mathrm{k}$ times variance at first Lag, Or:

$V R(k)=\frac{1}{q} \frac{\sigma_{k}^{2}(k)}{\sigma_{1}^{2}(k)}=1$

Two test statistics, $\mathrm{Z}_{1}(\mathrm{k})$ and $\mathrm{Z}_{2}(\mathrm{k})$ were developed by Lo and Mackinlay [30,31] (Lo and McKinlay, 1988; Lo and McKinlay, 1989) in order to account for homoscedastic and heteroscedastic error terms.

\subsubsection{Automatic VR test of Choi}

Selection of lag $k$ is important while testing weak form EMH using VR tests. Often, the lags are selected in an arbitrary fashion. Choi [32] (1999) used a quadratic spectral (QS) kernel based method to determine the optimal value of $k$. Andrews [33] (1991) stated that QS kernel has the ability in calculating the spectral density at zero frequency. Hence, it was employed

VR estimator of Choi is then defined as:

$V R(k)=1+2 \sum_{i=1}^{T-1} h(i / k) \hat{\rho}(i)$

Here, $\hat{\rho}(i)$ is the autocorrelation function, and $h(x)$ is the QS window

The normalized statistic is calculated as:

$V R_{f}=\frac{V R(k)-1}{(2)^{\frac{1}{2}}(T / k)^{-1 / 2}}$

Under $\mathrm{H} 0, V R_{f}$ follows asymptotic standard normal distribution.

\subsubsection{Wright's Non-Parametric Variance Ratio Tests}

Due to the parametric nature of Lo-MacKinlay test, small sample results were found to be biased. Wright [34] (2000) proposed a non-parametric VR test using signs and ranks to overcome this bias. As rank $(R 1$ and
$R 2$ ) and sign ( $S 1$ and $S 2$ ) tests have an exact sampling distribution, there is no need to approximate the asymptotic distribution. Further, these tests outperform the conventional VR tests while tested against data containing autocorrelation and fractional integration.

\subsubsection{VR Test of Richardson and Smith}

If the VR test statistics are computed over long lags with overlapping observations, the conventional parametric tests could not be used to draw useful inference as the distribution of the VR test becomes non-normal. To address this shortcoming, Richardson and Smith [35] (1991) suggested a joint test based on the following Wald statistic. The statistic is defined as:

$R S(k)=T\left(V R-1_{k}\right)^{\prime} \phi^{-1}\left(V R-1_{k}\right)$

VR is the $(k \times 1)$ vector of sample $k \mathrm{VRs}$, is the $(k$ $\times 1)$ unit vector and is the covariance matrix of VR. The joint $R S(k)$ statistic follows a $\chi^{2}$ distribution with $k$ degrees of freedom.

\subsubsection{Chow and Denning multiple VR test}

Chow and Denning [36] (1993) observed that the individual VR tests lack the ability to see whether all the variance ratios at different lags are equal to 1 simultaneously. This is a requirement to reject the RWH. Further, individual VR tests fail to control for the overall test size, resulting in the probability of a Type 1 error. The Chow and Denning test controls the joint test size and facilitate a comparison of variance ratios at multiple lags by employing Studentized Maximum Modulus (SMM) critical values. Chow and Denning statistics are calculated as follows:

$Z^{*}(\mathrm{~K})=\operatorname{Max}_{1 \leq i \leq K}\left|Z_{1}\left(k_{i}\right)\right|$
$Z^{*}(\mathrm{~K})=\operatorname{Max}_{1 \leq i \leq K}\left|Z_{2}\left(k_{i}\right)\right|$

$\mathrm{Z}_{1}(\mathrm{k})$ and $\mathrm{Z}_{2}(\mathrm{k})$ is calculated same as in Lo and MacKinlay $[30,31](1988,1989)$.

Here, $\left(q_{i}\right)$ are the different lags for $\left\{q_{i} \mid i=1,2, \ldots, m\right\}$. Acceptance or rejection of the null hypothesis is based on the maximum absolute value of individual variance ratio test statistics.

\subsubsection{Chen and Deo Joint VR Test}

Chen and Deo [37] (2006) Variance ratio test is based on a power transformation of the VR statistic. The 
transformation is used to achieve a better approximation to the normal distribution in finite samples with small lags $\mathrm{k}$. Further, the test statistic is found to be performing well against possible conditional heteroscedasticity present in the data.

\subsubsection{Escanciano and Lobato Test for Autocorrelation}

Escanciano and Lobato [38] (2009) automatic portmanteau test is employed to test the dependence structure in a given financial time series. The test statistic is defined as:

$A Q=T \sum_{i=1}^{p}\left(\widetilde{\rho}_{l}\right)^{2}$

$\widetilde{\rho_{l}}$ is the estimated autocorrelation coefficients from lags $i$ to $p$. The optimal lag length is determined using Akaike or Bayesian information criterion.

2.1.8 Dominguez and Lobato Test for non-linear dependence

Dominguez and Lobato [39] (2003) proposed test for nonlinear dependence in a time series. The test is based on Cramer-von Mises (CM) and Kolmogorov-Smirnov (KS)statistics. For a time series, the test statistics are defined as :

$C M=\frac{1}{\hat{\sigma}^{2} T^{2}} \sum_{j=1}^{T}\left[\sum_{t=1}^{T}\left(Y_{t}-\bar{Y}\right) 1\left(\tilde{Y}_{t-p} \leq \tilde{Y}_{j-p}\right)\right]^{\wedge} 2$

$K S=\max (1 \leq \mathrm{i} \leq T)\left|\frac{1}{\widehat{\sigma} \sqrt{T}} \sum_{t=1}^{T}\left(Y_{t}-\bar{Y}\right) 1\left(\tilde{Y}_{t-p} \leq \tilde{Y}_{j-p}\right)\right|(11)$

Where $\tilde{Y}_{t-p}=\left(Y_{t}, Y_{t-1} \ldots \ldots Y_{t-p}\right), 1()$ is an indicator function and $\mathrm{p}$ is the non-negative lag. They obtain the asymptotic $\mathrm{p}$ values for the statistics from a wild bootstrap method.

2.2 Alternatives to Efficient Market Hypothesis: The Adaptive Market Hypothesis

In AMH, Lo [40] (2004) stated that the market participants adapt according to the prevailing conditions, and the market switches between states of efficiency and inefficiency. He proposed an intuitive method to test this hypothesis by estimating rolling window first-order autocorrelation. If the market is efficient, the value of AC should be zero. The deviation of AC from its theoretical minimum can provide the degree of inefficiency at any given period.

Another common method to test AMH is the estimation of rolling window Hurst coefficient. Hurst coef- ficient was proposed by Hurst [41] in order to test longmemory or self-similarity in a time series. Hurst introduced Hurst coefficient to model the water flow in the river Nile. Existence of long memory in a financial time series provides the possibility of price forecasting its behavior. Further, such information could be of use to investors to design investment strategies and risk diversification. Hurst exponent is estimated through different methods. The basic formulation is explained as follows.

Let $\mathrm{x}_{\mathrm{t}}$ be a stationary time series and $\lambda \tau$ be its autocovariance function at lag $\tau$. Then, the asymptotic property of the auto-covariance function is given as follows:

$\lambda_{\tau} \approx|\tau|^{-\alpha} f(\tau)$ as $|\tau| \rightarrow \infty$

Where $\alpha(0,1)$ and $f(\tau)$ is a slowly varying function at infinity. The degree of long memory is given by the exponent $\alpha$; smaller the exponent, longer the persistence. The Hurst Exponent and $\alpha$ are related in the following way: $H=\frac{2-\alpha}{2}$

$\mathrm{H}$ lies in the range $0 \leq \mathrm{H} \leq 1$. If $\mathrm{H}=0.5$, then the series is said to be uncorrelated. $\mathrm{H}$ implies long memory or persistence in the return series. If the prices or returns are exhibiting an upward momentum in this period, it would persist in the next period and vise versa. Hsuggests short memory or mean reversion in the series. With short memory, an upward trend in this period would be followed by a downward trend in the next period and vise versa. For a market that is weak form EMH, the Hurst coefficient should have a value of 0.5.

Using the aforementioned measures, Kumar et.al. [42] (2020) proposed the adaptability index (AI). AI is formulated as follows:

$A I=\left((H-0.5)^{2}+\left(\frac{A C F}{2}\right)^{2}\right)^{0.5}$

$\mathrm{H}$ is the Hurst coefficient and ACF is the first-order autocorrelation coefficient. ACF is rescaled using its maximum (1) and minimum (-1) values for comparability. If a market is efficient, $\mathrm{H}=0.5$ and $\mathrm{ACF}=0$, hence $\mathrm{EI}=0$. The extent of deviation of EI from its theoretical minimum can explain the degree of inefficiency present in the market at any given time. $\mathrm{H}$ and ACF are included in the index as both of them are bounded. While autocorrelation captures the nature of dependence, the Hurst coefficient measure the 'memory' present in the series. We estimate the EI over a rolling window of 500 observations in order to dynamically test for $\mathrm{AMH}$ in the wine market. 


\section{RESULTS AND DISCUSSION}

Before proceeding to the evaluation of test results, we estimate the summary statistics for the LIV-EX 50 return series. We present the results in Table 1. Here, we estimate basic summary statistics like minimum, maximum, mean, standard deviation, skewness and kurtosis along with the Jarque-Bera test to see if the returns are normally distributed. Further, we employ Ljung-Box test and Box-Pierce test to see if the returns exhibit autocorrelation. From the minimum and maximum values, we can find the range in which the returns are moving. From the skewness measure, we can see whether the return distribution is symmetric. From Kurtosis, we can see if the return distribution is fat-tailed, i.e. whether there are extreme fluctuations in the return series. The returns are found to be oscillating within the range of $-3.2 \%$ and $5.6 \%$, as evidenced by the maximum and minimum value of the returns. From the skewness and kurtosis values, we can see that the returns are positively skewed and exhibit fat tails. The Jarque-Bera test checks the null of normal distribution. From the p-value, we can infer that the null hypothesis is rejected and the return series is not normally distributed. The null of no autocorrelation is rejected for both Ljung-Box and Box-Pierce test at a lag of 5, as evidenced from the p-value. Thus, presence of autocorrelation in the LIV-EX 50 return series is confirmed.

From the diagnostic testing, we can infer certain things. First, the LIVE-EX 50 returns are skewed, indicating possible asymmetry. We see evidence of fat-tails, pointing towards increased activity at the tails. These two findings are confirmed by the Jarque-Bera statistic result that the returns are non-normally distributed. The two autocorrelation test results point towards the presence of a dependence structure in the return series. Next, we evaluate the statistical test results. We apply the tests on the whole sample and on four non-overlapping sub-samples of equal length. The sub-samples testing is employed to see if information efficiency is episodic in nature. We present the results in Table 2.

Here, Lo-McKinlay and Choi are individual VR tests whereas Chen-Deo, Chow-Denning, Richardson and Smith and Wright are joint VR tests. In the individual VR tests, the weak form EMH is tested at separate holding periods. In the case of joint VR tests, the null of EMH is jointly tested for all the holding periods. We decided the holding periods as 2,5,10 as suggested by [43].

First, we go through the test results for the entire sample. The Lo-Mac(M1) statistics reject the null of weak form efficiency for the lags 5 and 10. However, when we account for heteroscedasticity (the M2 sta-
Table 1. Summary statistics.

\begin{tabular}{lc}
\hline Statistic & Value \\
\hline Minimum & -0.032353 \\
Maximum & 0.05631 \\
Mean & $4.06 \mathrm{E}-05$ \\
Stand. Deviation & 0.0028422 \\
Skewness & 1.264 \\
& $(0.000)$ \\
Excess Kurtosis & 53.506 \\
& $(0.000)$ \\
Jarque-Bera(JB) & 532610 \\
& $(0.000)$ \\
Ljung-Box(5) & 58.094 \\
& $(0.000)$ \\
Box-Pierce(5) & 11.6040 \\
\end{tabular}

Note: $\mathrm{P}$ values are provided in the parenthesis

tistics), the returns are found to be weak form efficiency. Looking into the Automatic VR Test results (Choi), we can see that the null of EMH is not rejected for the whole sample. Among the joint VR tests, Wald test and Wright's joint rank and sign test results suggest that the wine market is informationally inefficient whereas Chen-Deo and Chow-Denning test results do not reject the null of weak form efficiency. Looking into the test results for serial dependence, the Escariano and Lobato test result does not reject of linear dependence structure. However, the Dominic-Lobato test results reject the null non-linear independence. The Hurst coefficient is 0.552 and statistically significant and thus confirms weak long memory. Overall, the results are mixed. VR test results give some indication towards weak form inefficiency. The presence of non-linear dependence and long memory in the return series is confirmed. The mixed nature of result warrants more examination to see if weak form EMH is an episodic phenomenon. Towards this, we examine the test results estimated for the four non-overlapping sub-samples.

In case of the first sub-sample, Lo-Mac M1 statistics reject the null of weak form EMH at holding periods 2 and 5 whereas M2 does not reject the null hypothesis. Choi test also cannot reject the null of EMH. Among the joint VR test results, Wright's test result shows that the sub-sample is weak form inefficient, whereas ChoDenning and Chen-Deo test result confirm that the subsample is weak form efficient. Escariano and Lobato test result do not reject of linear dependence structure while Dominic-Lobato test confirm non-linear dependence. The Hurst coefficient value is 0.568 and statistically significant, showing weak persistence. 
Table 2. Test results.

\begin{tabular}{|c|c|c|c|c|c|c|}
\hline Statistics & & Whole Sample & Subsample1 & Subsample2 & Subsample3 & Subsample4 \\
\hline \multirow[t]{3}{*}{ Lo-Mac M1 } & 2 & 1.554 & 0.826 & -1.323 & 0.864 & $-2.424^{\star \star}$ \\
\hline & 5 & $4.507^{\star *}$ & $2.272^{\star *}$ & -0.156 & $4.892^{* * *}$ & -1.408 \\
\hline & 10 & $4.315^{\star *}$ & 2.074 & 1.847 & $8.094^{\star * *}$ & -0.073 \\
\hline \multirow[t]{3}{*}{ Lo-Mac M2 } & 2 & 0.464 & 0.476 & -1.148 & 0.775 & $-2.191^{\star \star}$ \\
\hline & 5 & 1.424 & 1.385 & -0.143 & $4.305^{\star * *}$ & -1.250 \\
\hline & 10 & 1.443 & 1.338 & 1.705 & $7.060^{* * *}$ & -0.065 \\
\hline Choi & $\begin{array}{c}1.787 \\
(0.454)\end{array}$ & $\begin{array}{c}0.466 \\
(0.634)\end{array}$ & $\begin{array}{c}-0.738 \\
(0.320)\end{array}$ & $\begin{array}{c}2.927 \\
(0.002)\end{array}$ & $\begin{array}{l}-1.856 \\
(0.030)\end{array}$ & \\
\hline \multirow[t]{2}{*}{ Chow-Denning $(2,5,10)$} & CD1 & $4.507^{* * *}$ & 2.272 & 1.847 & $8.094^{* * *}$ & $2.424^{* *}$ \\
\hline & $\mathrm{CD} 2$ & 1.443 & 1.385 & 1.705 & $7.060^{* * *}$ & 2.191 \\
\hline Chen- Deo $(2,5,10)$ & 2.832 & 2.701 & $12.001^{\star *}$ & $33.839^{* * *}$ & $8.576^{* *}$ & \\
\hline RS Wald $(2,5,10)$ & $26.798^{\star * *}$ & 6.672 & $16.105^{\star * \star}$ & $86.564^{* \star *}$ & $9.292^{\star *}$ & \\
\hline$\overline{J R 1}(2,5,10)$ & $15.359^{\star * *}$ & $15.205^{\star * *}$ & 1.941 & $6.732^{\star * *}$ & 1.655 & \\
\hline JR2 $(2,5,10)$ & $18.023^{\star * *}$ & $15.118^{\star * *}$ & 1.621 & $6.998^{\star * *}$ & 2.101 & \\
\hline JS1 $(2,5,10)$ & $9.346^{\star * *}$ & $10.262^{* * *}$ & $2.358^{\star *}$ & $4.638^{\star * \star}$ & 1.256 & \\
\hline \multirow[t]{2}{*}{ Dominguez and Lobato } & $\mathrm{CM}$ & $\begin{array}{c}0.472 \\
(0.000)\end{array}$ & $\begin{array}{c}0.514 \\
(0.030)\end{array}$ & $\begin{array}{c}0.578 \\
(0.010)\end{array}$ & $\begin{array}{c}0.170 \\
(0.280)\end{array}$ & $\begin{array}{c}0.452 \\
(0.050)\end{array}$ \\
\hline & KS & $\begin{array}{c}1.135 \\
(0.000)\end{array}$ & $\begin{array}{c}1.109 \\
(0.060)\end{array}$ & $\begin{array}{c}1.387 \\
(0.030)\end{array}$ & $\begin{array}{c}1.068 \\
(0.120)\end{array}$ & $\begin{array}{c}1.388 \\
(0.050)\end{array}$ \\
\hline Escanciano and Lobato(ES) & $\begin{array}{c}0.215 \\
(0.643)\end{array}$ & $\begin{array}{c}0.226 \\
(0.633)\end{array}$ & $\begin{array}{c}1.242 \\
(0.265)\end{array}$ & $\begin{array}{l}87.960 \\
(0.000)\end{array}$ & $\begin{array}{c}4.776 \\
(0.026)\end{array}$ & \\
\hline$\overline{\text { Hurst coefficient }(\mathrm{H})}$ & $\begin{array}{c}0.552 \\
(0.000)\end{array}$ & $\begin{array}{c}0.568 \\
(0.000)\end{array}$ & $\begin{array}{c}0.696 \\
(0.000)\end{array}$ & $\begin{array}{c}0.559 \\
(0.000)\end{array}$ & $\begin{array}{c}0.731 \\
(0.000)\end{array}$ & \\
\hline
\end{tabular}

Note: In table 2, Lo-Mac M1 and M2 stands for Lo-McKinlay VR test statistics, with homoscedastic and heteroscedastic errors. Choi stands for Choi's automatic VR test. Similarly, Chow Denning CD1 and CD2 denotes the Chow-Denning Joint VR test statistics with homoscedastic and heteroscedastic errors. Chen-Deo stands for Chen and Deo's joint VR test. Wald test statistic of Richardson and Smith is denoted by RS Wald. Wright's joint rank and sign VR test statistics are denoted by JR1, JR2 and JS1.The Crammer-Von and Kolmogorov-Smirnov statistic of Dominiguez and Lobato are represented by CM and KS. Similarly, Escanciano and Lobato test statistic is represented by ES. The measure for long memory, i.e. Hurst coefficient is denoted by $\mathrm{H}$. The $\mathrm{p}$ values are presented in the parenthesis. The symbols ${ }^{* *}$ and ${ }^{* *}$ indicates the rejection of the null hypothesis of weak form efficiency at $1 \%$ and $5 \%$ significance respectively

In the second sub-sample, both Lo-Mac and Choi test results do not reject the null of weak form EMH. Among joint VR tests; Chen-Deo, Chow-Denning and Wald test results confirm weak form EMH in the subsample whereas the Wright test results showing that the sub-sample is weak form inefficient. Escariano and Lobato test result show absence of linear dependence structure where Dominic-Lobato test results confirm non-linear dependence in the sub-sample. Hurst coefficient value is 0.696 and statistically significant, showing moderate persistence or long memory.

In the third sub-sample, we can see that all the variance ratio tests (except Lo-Mac M1 and Lo-Mac M2 at lag 2) reject the null of weak form efficiency. Looking into the Escariano and Lobato test result, we can confirm presence of linear dependence structure. However,
Dominic-Lobato test results show the absence of nonlinear dependence in the sub-sample. The Hurst coefficient value is 0.559 and statistically significant, pointing towards the existence of weak persistence.

In the fourth sub-sample, it is seen that the null of weak form EMH is rejected for Lo-Mac M1 and Lo-Mac M2 at lags 2, whereas it is not rejected at other lags. Choi test result indicates that the sub-sample is weak form inefficient. Choi-Denning (CD1) statistic value shows that the series is weak form inefficient. However, when we consider heteroscedastic errors (CD2), the null of weak form EMH is not rejected. Both Chen-Deo and Wald test results show that the sub-sample is weak form efficient. However, the Wright test results show that the sub-sample is weak form efficient. Escariano and Lobato test result confirms linear dependence while Dominic- 
Lobato test results indicate non-linear dependence in the sub-sample. The Hurst coefficient is statistically significant with a value is 0.731 , showing strong persistence in the sub-sample.

Looking into the results, we see a mixed picture. VR test results show mixed evidence regarding weak form efficiency of the wine market. Further, there is evidence of non-linear dependence in the return series. The presence of long memory across all the four sub-samples indicates persistence in the return series. In this context, it would be ideal to study the market efficiency in a time varying context. Towards this, we estimate the AI over a rolling window of 500 length. We present the result in Figure 1.

From the plot, it is clear that the wine market oscillates between relative states of efficiency and inefficiency. However, it never touches the theoretical minimum zero, indicating that the wine market was never truly efficient. The market becomes more inefficient as the AI values move away from zero. During times of extreme market movements, any dependence structure present in the market will be lost because of the prevailing uncertainty and market volatility, resulting in AI values being close to zero.

We identify the first dip in wine prices around end of 2012. This period coincides with the Chinese-lead Bordeaux bubble collapse. With the post 2008 economic boom in China, the demand for fine wine increased mul- tifold. Majority of the demand was aimed at fine wine produced in the Bordeaux region of France. Fine wine was mainly employed as a gift in China. This increased demand resulted in a steep rise of fine wine prices, resulting in the asset bubble. For example, a case of Chateau Margaux 2000 cost $£ 10,500$ during the peak of the bubble.

The building of the asset bubble is characterized by the increased AI values, indicating the increasing returns in the market. This is in line with the earlier results that wine prices are influenced by Economic growth[30] (Jiao,2016). However, with the 2011 anti-corruption drive in China, demand for fine wine as a gift steeply declined, resulting in the bubble's collapse. The same is characterized in the plot by the decreasing AI values. Next, we see a drop in AI values between January-June 2013. The possible reason for the decrease in the AI values is the QE3 tapering by US FED in 2013. Later, we see AI values exhibiting a decline, starting from 2014 January. This period coincides with the US FED's tapering of the bond-buying back program starting in January 2014. The AI reaches its minimum value around June 2014, coinciding with then FED chairman Bernanke's announcement regarding QE tapering and the resultant stock market crash in June 2014. [30] had shown that macroeconomic factors indirectly influence wine prices through shocks from the financial markets

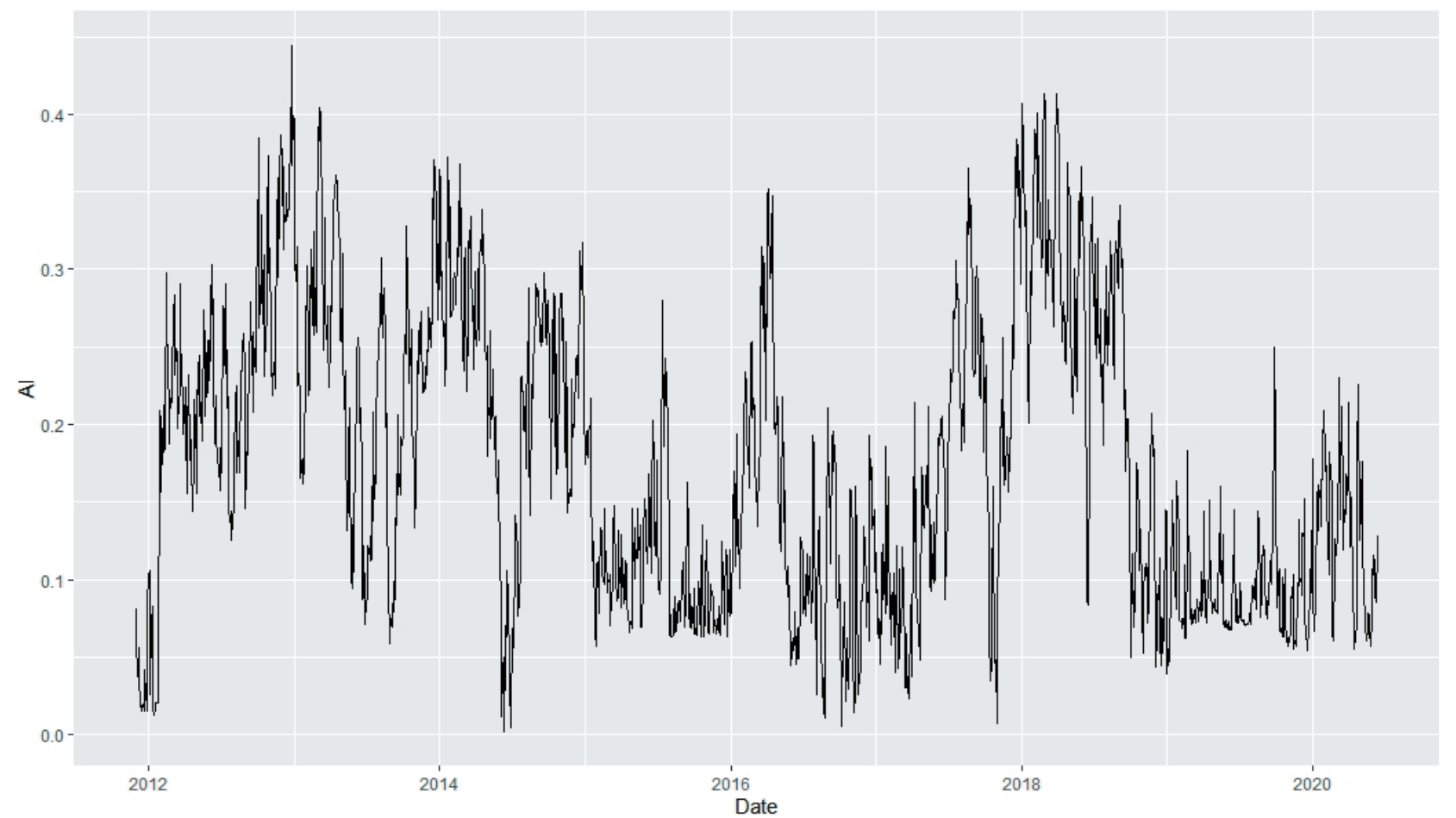

Figure 1. The adaptability index plot. 
via the channels such as wealth effect, cash effect and volatility transmission. Further, there is a direct but delayed impact. The AI values suggest that the QE 3 tapering and the resultant economic turbulence affected wine prices. Later, we find a drop in AI values starting around the first quarter of 2016. This period coincides with the Brexit announcement and the subsequent turmoil in the wine market. UK is one of the largest wine markets in the world. Therefore, leaving the EU affects the wine market in two ways. First, the import tariffs will undergo a change. The earlier free trade agreements with the EU will no longer be applied. The increased tariffs will have a negative impact on wine consumption because of the price rise. Second, the depreciation of Pound since Brexit makes wine imports costlier and driving its prices up and may cause a price bubble. We see a recovery around the beginning of 2017 with the AI values reaching its peak by mid-2017 and then drop. Bordeaux Index grew $43 \%$ in the first six months of 2017, compared to the same period in 2016. [31] found evidences of an asset bubble during this period because of the exchange rate fluctuations. The collapse of the 2017 bubble is characterized by decreasing AI values post June 2017. The period 2019-20 is characterized by low AI values (oscillating between 0.2 and 0.05 ), indicating that the market was relatively efficient during this period. If we analyze the wine market's response to the Covid-19 crisis, we can see no significant fluctuations in the AI, indicating that wine market was not significantly affected by the Covid-19 induced economic crisis so far. However, a delayed impact cannot be ruled out.

\section{CONCLUDING REMARKS}

The purpose behind this study was to analyze nature of informational efficiency in the wine market. To achieve our objective, we used six variance ratio tests and two tests for serial dependence on the daily returns of LIV-EX 50. We applied the tests on the whole sample and four equally sized non-overlapping sub-samples to see if weak form efficiency could be categorized as episodic. We estimated Hurst coefficient to test for the presence of long memory in the data. The statistical tests exhibited mixed results regarding weak form efficiency, while the Hurst coefficient values confirmed long memory. Further, presence of non-linear dependence was detected. Considering these factors, we tested the dynamic nature of information efficiency by estimating the adaptability index (AI) for the LIV-EX 50 returns over a rolling window of length 500.The AI values showed that the wine market is periodically oscillating between states of relative efficiency and inefficiency. We use the word relative as AI never reached its theoretical minimum value of zero. Periods of inefficient behavior often coincided with episodes of economic turmoil. Our analysis revealed that the Wine market was adversely affected by events such as the Bordeaux wine price bubble, the Quantitative Easing 3 (QE3) tapering by US FED, Brexit and Covid-19. Our results confirm the findings of [44], that wine markets are influenced by Macroeconomic fluctuations directly and indirectly.

Regarding market efficiency, our results confirm the findings of [29], indicating that wine market is informationally inefficient. However, our study reveals that the notion of informational efficiency in wine market is dynamic than static. That is, the market participants adapt according to the prevailing market conditions. Therefore, our study extends the work carried out by [29].

From the AI values, we can see that the wine market switches between states of relative efficiency and inefficiency. An inefficient market implies that the wine returns do not follow a random walk and there can be predicted. Hence, there is chance of excess profit to be made. Further, When the market is the in period of inefficiency, the Wine prices do not reflect all the available information, enabling the market participants to incorporate their own hidden information set while creating strategies and reap extra gains. However, this would not be desirable in the long run, as mispricing of assets invariably leads to asset bubbles and market crashes [45]. Therefore, from a policy perspective, it would be better to make wine market related information to be more accessible to all stakeholders so that the information asymmetry in the market could be minimized.

Our results reveal that the wine market was largely unaffected by the COVID-19 induced financial shock. From an investor perspective, this is a positive news, as wine could be employed as a safe haven instrument during times of crisis. Our results reiterate the safe haven property of Wine market, previously discussed by [19] and [21]. For practical purposes, the AI could be used as an indicator to measure relative market efficiency at any point. If AI values are away from zero, there is a dependence structure present in the market and it may persist for some time. An investor could employ appropriate models to identify the nature of persistence and design necessary trading strategies.

To conclude, it is better to treat information efficiency as a dynamic concept rather than a static notion. Our results conclusively proved the dynamic nature of information efficiency of the wine market and confirmed the safe haven property of wine. We suggest investors to consider these aspects while making investment decisions. 


\section{REFERENCES}

[1] E.F. Fama, The behavior of stock-market prices, J. Bus. 38 (1965) 34-105.

[2] S. Khuntia, J.K. Pattanayak, G.S. Hiremath, Is the foreign exchange market efficiency adaptive? The empirical evidence from India, J. Asia-Pacific Bus. 19 (2018) 261-285.

[3] A.W. Lo, The adaptive markets hypothesis, J. Portf. Manag. 30 (2004) 15-29.

[4] G.S. Hiremath, J. Kumari, Stock returns predictability and the adaptive market hypothesis in emerging markets: evidence from India, Springerplus. 3 (2014) 428.

[5] G.S. Hiremath, S. Narayan, Testing the adaptive market hypothesis and its determinants for the Indian stock markets, Financ. Res. Lett. 19 (2016) 173-180.

[6] J.H. Kim, A. Shamsuddin, K.-P. Lim, Stock return predictability and the adaptive markets hypothesis: Evidence from century-long US data, J. Empir. Financ. 18 (2011) 868-879.

[7] C.J. Neely, P.A. Weller, J.M. Ulrich, The adaptive markets hypothesis: evidence from the foreign exchange market, J. Financ. Quant. Anal. (2009) 467-488.

[8] M.N. Shahid, M. Jehanzeb, A. Abbas, A. Zubair, M.A.H. Akbar, Predictability of precious metals and adaptive market hypothesis, Int. J. Emerg. Mark. (2019).

[9] M.M. Ghazani, S.B. Ebrahimi, Testing the adaptive market hypothesis as an evolutionary perspective on market efficiency: Evidence from the crude oil prices, Financ. Res. Lett. 30 (2019) 60-68.

[10] J. Chu, Y. Zhang, S. Chan, The adaptive market hypothesis in the high frequency cryptocurrency market, Int. Rev. Financ. Anal. 64 (2019) 221-231.

[11] S. Khuntia, J.K. Pattanayak, Adaptive market hypothesis and evolving predictability of bitcoin, Econ. Lett. 167 (2018) 26-28.

[12] P.Masset, C. Henderson, Wine as an alternative asset class. Journal of Wine Economics, 5(1) (2010),87-118.

[13] J.J. Fogarty,Wine investment and portfolio diversification gains. Journal of Wine Economics, 5(1) (2010),119-131.

[14] J.J. Fogarty,C. Jones, Return to wine: a comparison of the hedonic, repeat sales and hybrid approaches. Australian Economic Papers 50(4)(2011), 147-156.

[15] L. Baldi, M. Peri, D. Vandone, Investing in the wine market: a country-level threshold cointegration approach. Quantitative Finance, 13(4)(2013), 493-503.
[16] J.J. Fogarty, R. Sadler, To save or savor: A review of approaches for measuring wine as an investment. Journal of Wine Economics, 9(3)(2014), 225-248.

[17] E. Dimson, P. Rousseau, C. Spaenjers, The price of wine. Journal of Financial Economics, 118 (2) (2015),431-449

[18] B.Faye,E. Le Fur, S. Prat, Dynamics of fine wine and asset prices: evidence from short-and long-run co-movements. Applied Economics, 47(29)(2015), 3059-3077.

[19] E.I. Bouri, Fine wine as an alternative investment during equity market downturns, J. Altern. Investments. 17 (2015) 46-57.

[20] E. Le Fur, H.B. Ameur, B. Faye, Time-varying risk premiums in the framework of wine investment. Journal of Wine Economics, 11(3)(2016) , 355 - 378

[21] E.I. Bouri, D. Roubaud, Fine Wines and Stocks from the Perspective of UK Investors: Hedge or Safe Haven? Journal of Wine Economics, 11(02) (2016), 233-248.

[22] B.Aytaç,C. Mandou, Wine: To drink or invest in? A study of wine as an investment asset in French portfolios. Research in International Business and Finance, 36(2016), 591-614.

[23] S. Introvigne, E. Bacchiocchi, D. Vandone, A cointegration analysis of wine wine stock indexes. Risk Governance and Control: Financial Markets \& Institutions. 7(4-2)(2017), 178-188

[24] J.M. Cardebat, L. Jiao, The long-term financial drivers of fine wine prices: The role of emerging markets. The Quarterly Review of Economics and Finance, 67(2018), 347-361.

[25] E. Bouri, R. Gupta, W.-K. Wong, Z. Zhu, Is wine a good choice for investment?, Pacific-Basin Financ. J. 51 (2018) 171-183

[26] P. Masset, J.P. Weisskopf, Raise your glass: Wine investment and the financial crisis. In World Scientific Reference on Handbook of the Economics of Wine: Volume 1: Prices, Finance, and Expert Opinion (2018),271-295

[27] K. Storchmann, Wine economics, J. Wine Econ. 7 (2012) 1-33.

[28] E.I. Bouri, Beyond the negative relation between return and conditional volatility in the wine market, Int. J. Wine Bus. Res. (2014). 279-294

[29] E. Bouri, T. Chang, R. Gupta, Testing the efficiency of the wine market using unit root tests with sharp and smooth breaks, Wine Econ. Policy. 6 (2017) 80-87.

[30] A.W. Lo, A.C. McKinlay, Stock market prices do not follow random walks: Evidence from a simple specification test, Rev. Financ. Stud. 1 (1988) 41-66. 
[31] A.W. Lo, A.C. McKinlay, The size and power of the variance ratio test in finite samples: A Monte Carlo investigation, J. Econom. 40 (1989) 203-238.

[32] I. Choi, Testing the random walk hypothesis for real exchange rates, J. Appl. Econom. 14 (1999) 293-308.

[33] D.W.K. Andrews, Heteroskedasticity and autocorrelation consistent covariance matrix estimation, Econom. J. Econom. Soc. (1991) 817-858.

[34] J.H. Wright, Alternative variance-ratio tests using ranks and signs, J. Bus. Econ. Stat. 18 (2000) 1-9.

[35] M. Richardson, T. Smith, Tests of financial models in the presence of overlapping observations, Rev. Financ. Stud. 4 (1991) 227-254.

[36] K.V. Chow, K.C. Denning, A simple multiple variance ratio test, J. Econom. 58 (1993) 385-401.

[37] W.W. Chen, R.S. Deo, The variance ratio statistic at large horizons, Econom. Theory. (2006) 206-234.

[38] J.C. Escanciano, I.N. Lobato, An automatic portmanteau test for serial correlation, J. Econom. 151 (2009) 140-149.

[39] M.A. Domínguez, I.N. Lobato, Testing the martingale difference hypothesis, Econom. Rev. 22 (2003) 351-377.

[40] A. Lo . The Adaptive Markets Hypothesis: Market Efficiency from an Evolutionary Perspective, The Journal of Portfolio Management 30th Anniversary Issue 30 (5)(2004), 15-29

[41] H.E. Hurst, Long-term storage capacity of reservoirs, Trans. Amer. Soc. Civ. Eng. 116 (1951) 770799.

[42] A.S. Kumar, T. Nagaraju, T. Ajaz, On the Informational Efficiency of the Cryptocurrency Market, IUP J. Appl. Econ. 19 (2020).

[43] R.S. Deo, M. Richardson, On the asymptotic power of the variance ratio test, Econom. Theory. (2003) 231-239.

[44] L. Jiao, Macroeconomic determinants of wine prices. The American Association of Wine Economists, AAWE Working Paper, 2016.

[45] C.-W. Su, L.I. Xin, When will bubbles occur in the fine wine market?, Econ. Comput. Econ. Cybern. Stud. Res. 54 (2020). 